\title{
Especie nueva de Heliocarpus (Tiliaceae), de la depresión del río Balsas, Guerrero, México
}

\author{
A new species of Heliocarpus (Tiliaceae) from the Balsas River Basin, Guerrero, Mexico
}

\author{
Martha Gual-Díaz y Elizabeth Moreno-Gutiérrez² \\ ${ }^{l}$ Laboratorio de Plantas Vasculares, Departamento de Biología, Facultad de Ciencias, Universidad Nacional Autónoma de México. Ciudad \\ Universitaria, Delegación Coyoacán, 04510, México D.F., México. \\ ${ }^{2}$ Comisión Nacional para el Conocimiento y Uso de la Biodiversidad (CONABIO). Avenida Liga Periférico-Insurgentes Sur 4903, Col. Parques del \\ Pedregal, Delegación Tlalpan 14010, México D.F., México. \\ *Correspondencia:mgual@conabio.gob.mx
}

\begin{abstract}
Resumen. Se describe e ilustra Heliocarpus parvimontis M. Gual, del cerro Xilotzin, situado en la parte oriental de la depresión del río Balsas, en el municipio de Xochihuehuetlán, Guerrero, México. Pertenece a un grupo de 6 especies de Heliocarpus, distribuidas en México, con ovario y fruto sésiles sobre el androginóforo. Está más relacionada morfológicamente con $\mathrm{H}$. occidentalis Rose, de la cual se diferencia por la textura de la corteza, indumento, color, margen y cantidad de glándulas en la lámina de la hoja, así como por la forma de los sépalos, por el número de estambres y por la forma de las ectoaberturas del polen. Se incluye una clave sinóptica para identificar las 6 especies relacionadas y un cuadro comparativo entre las 2 especies.
\end{abstract}

Palabras clave: Guerrero, Heliocarpus parvimontis sp. nov., México.

\begin{abstract}
Heliocarpus parvimontis M. Gual, from the Cerro Xilotzin, at the eastern part of the Balsas River Basin in the municipality of Xochihuehuetlán, Guerrero, Mexico, is described and illustrated. This species is morphologically similar to H. occidentalis Rose; both species belong to a group of 6 Mexican species with sessile ovary and fruit on an androgynophore. It differs from the latter species by bark texture, leaf blade indument, color, margin and amount of glands on leaves, the sepal shape, the number of stamens and the shape of the ecto-aperture of the pollen grain. A table comparing the distinguishing features of the 2 species and an identification key to the 6 related species are included.
\end{abstract}

Key words: Guerrero, Heliocarpus parvimontis sp. nov., Mexico.

\section{Introducción}

El género Heliocarpus, con aproximadamente 11-22 especies presenta una distribución neotropical (Lay, 1949; Robyns, 1964; McVaugh, 2001; Mabberley, 2002). En México, se conocen 10 especies (Lay, 1949), comunes en vegetación secundaria derivada de distintos tipos de bosques tropicales, como el caducifolio, el subcaducifolio, el perennifolio, el subperennifolio y el bosque de galería; son menos frecuentes en bosques templados (principalmente de Quercus o de Pinus-Quercus).

Hasta ahora, se conocía la distribución de 3 especies de Heliocarpus en el estado de Guerrero (Gual, 1998). Como resultado de las exploraciones tendientes a la elaboración de la Flora de Guerrero, se encontró una

Recibido: 07 febrero 2008; aceptado: 24 noviembre 2008 nueva especie, la cuarta en ese estado, cuyos especímenes presentan características diferentes con respecto a las 5 especies del grupo que presentan fruto y ovario sésil sobre un androginóforo (Lay, 1949): H. attenuatus S. Watson y H. palmeri S. Watson, con distribución en los estados de Sonora, Chihuahua y Sinaloa, habitando el bosque de PinusQuercus y bosques tropicales caducifolio y subcaducifolio; $H$. occidentalis Rose, con distribución en Nayarit, Jalisco, Colima, Michoacán, Guerrero, México, Oaxaca y Chiapas, habitando los bosques tropicales caducifolio y subcaducifolio, así como en vegetación secundaria (acahual); H. pallidus Rose, con distribución en Nayarit, Jalisco, Michoacán, Guerrero, México, Morelos Puebla y Oaxaca, habitando los bosques tropical caducifolio, de Quercus, de Pinus-Quercus y en vegetación secundaria (matorral) y $H$. terebinthinaceus (DC.) Hochr., con distribución en Nayarit, Jalisco, Michoacán, Guanajuato, 
México, Morelos, Guerrero, Oaxaca, y Chiapas, habitando en los bosques de galería, de Quercus y de Pinus-Quercus, así como en el bosque tropical caducifolio y en vegetación secundaria.

Al consultar la literatura pertinente, y los tipos depositados en los herbarios MICH, MO y NY, de las especies del grupo al que pertenece, se llegó a la conclusión de que la especie más cercana al nuevo taxon es $H$. occidentalis y que ninguna especie conocida presenta el conjunto de caracteres que se describen a continuación.

Heliocarpus parvimontis M. Gual, sp. nov. (Fig. 1). Tipo: México: Guerrero: municipio de Xochihuehuetlán: cerro Xilotzin, $3.25 \mathrm{~km}$ al NNE de Jilotepec, $1550 \mathrm{~m}$ snm, en bosque tropical caducifolio y en ecotonía de bosque tropical caducifolio-bosque de Quercus, 02 octubre 1993, E. Moreno 581 y M. A. Monroy (Holotipo MEXU; isotipo FCME).

Differt a $H$. occidentalis Rose cortice non exfolianti, foliis chlorinis, marginibus erosis cum lobis plerumque glandulosis, infra dense stellato-pubescentibus, sepalis lanceolatis, staminibus circa 50 et pollinis granis tricolporatis.

Arbustos de 1.5 a $3.0 \mathrm{~m}$ de alto. Tallos densamente estrellado-pubescentes, glabrescentes, con abundantes lenticelas de color blanco, corteza no exfoliante. Hojas con estípulas filiformes en la base del pecíolo, ca. 3 mm de largo, deciduas; pecíolos de 1.0-1.5 cm de largo, densamente estrellado-pubescentes; lámina entera, ovada o angostamente ovada, $3-8 \mathrm{~cm}$ de largo, 2-5 cm de ancho, con 5(-7) nervaduras, haz con pubescencia regular de pelos estrellados con brazos cortos y largos, envés con indumento abundante de pelos estrellados con brazos largos (dando una apariencia blanquecina), ligeramente aterciopelada, de color verde claro, ápice acuminado, base cuneada o ligeramente subcordada, margen eroso con la mayoría de los lóbulos glandulares. Inflorescencias terminales o axilares, paniculadas, $5-11 \mathrm{~cm}$ de largo, brácteas foliáceas, lanceoladas, ca. $2 \mathrm{~cm}$ de largo, con características similares a las de las hojas. Flores probablemente perfectas, ca. 1 cm de diámetro; cáliz con 5 sépalos lanceolados, 4.5-6.0 $\mathrm{mm}$ de largo, ca. $1 \mathrm{~mm}$ de ancho, cara adaxial glabra, cara abaxial cortamente estrellado-pubescente, apéndices 1-2 $\mathrm{mm}$ de largo; corola con 5 pétalos obovados, ca. $2 \mathrm{~mm}$ de largo, escasamente estrellado-pubescentes en la base, ápice asimétrico y denticulado; androginóforo ca. $5 \mathrm{~mm}$ de largo; estambres aproximadamente 50, filamentos ca. $5 \mathrm{~mm}$ de largo; ovario globoso, 2-locular, cada lóculo con 2 óvulos, ca. $5 \mathrm{~mm}$ de largo, marginalmente ciliado, estrellado-pubescente; estilo 2-5 mm de largo; estigma bilobado. Polen tricolporado. Carcérulo ovoide, comprimido lateralmente, estrellado-pubescente, 8-9 $\mathrm{mm}$ de largo, cerdas ca. $3 \mathrm{~mm}$ de largo, ocasionalmente presentes en las superficies ventral y dorsal. Semillas piriformes, una por lóculo, 3-5 mm de largo, ca. $3 \mathrm{~mm}$ de ancho, castaño claro en la madurez.

Paratipos. MÉXICO: Guerrero: municipio de Xochihuehuetlán: cerro Xilotzin, $3.25 \mathrm{~km}$ al NNE de Jilotepec, $1590 \mathrm{~m}$ snm, 24 octubre 1998, E. Moreno 1060, J. Jiménez y O. Alcántara (FCME; MEXU). Cerro Xilotzin, $3.25 \mathrm{~km}$ al NNE de Jilotepec, $1480 \mathrm{~m}$ snm, 24 octubre 1998, E. Moreno 1061, J. Jiménez y O. Alcántara (FCME; MEXU). Cerro Xilotzin, $3.25 \mathrm{~km}$ al NNE de Jilotepec, 1 $500 \mathrm{~m}$ snm, 25 octubre 1998, E. Moreno 1062, J. Jiménez y O. Alcántara (FCME; MEXU). Cerro Xilotzin, $3.25 \mathrm{~km}$ al NNE de Jilotepec, $1480 \mathrm{msnm}, 25$ octubre 1998, E. Moreno 1063, J. Jiménez y O. Alcántara (ENCB; FCME; IEB; MEXU).

Hábitat. Se desarrolla en laderas con pendiente moderada de orientación NNE, sobre suelo sedimentario pedregoso, en bosque tropical caducifolio y en zonas de ecotonía entre este bosque y el de Quercus, en altitudes de 1480 a 1590 $\mathrm{m}$.

Distribución. Restringida al estado de Guerrero, hasta el momento se conoce sólo de la localidad tipo.

Fenología. Se colectó en floración y fructificación en el mes de octubre.

Etimología. El epíteto específico significa "del monte pequeño", con referencia al nombre del cerro Xilotzin, que en maya significa "pequeño", sitio donde fueron colectados los especímenes.

\section{Comentarios taxonómicos}

Lay (1949) divide las especies del género en 2 grupos: el primero, con ovario y fruto sésil sobre un androginóforo; y el segundo, con ovario y fruto sobre un ginóforo por encima de un androginóforo. Con base en la revisión de los especímenes, $H$. parvimontis se ubica morfológicamente en el primero, previamente conformado por 5 especies. De este grupo, la especie más afín es $H$. occidentalis, compartiendo el sexo de las flores (perfectas; no se sabe con seguridad en la especie nueva), el número de pétalos (5) y sépalos (5), longitud del fruto $(0.4$ a $1.3 \mathrm{~cm})$, las hojas ovadas, enteras, no lobadas, con bases cuneadas y con 5(-7) nervaduras. A continuación se presenta una clave sinóptica para diferenciar las 6 especies que se ubican en este grupo y un cuadro comparativo (Cuadro 1) entre las estructuras distintivas de $H$. occidentalis y $H$. parvimontis.

Además de las diferencias indicadas en el Cuadro 1, H. parvimontis se ha encontrado hasta ahora en vegetación 


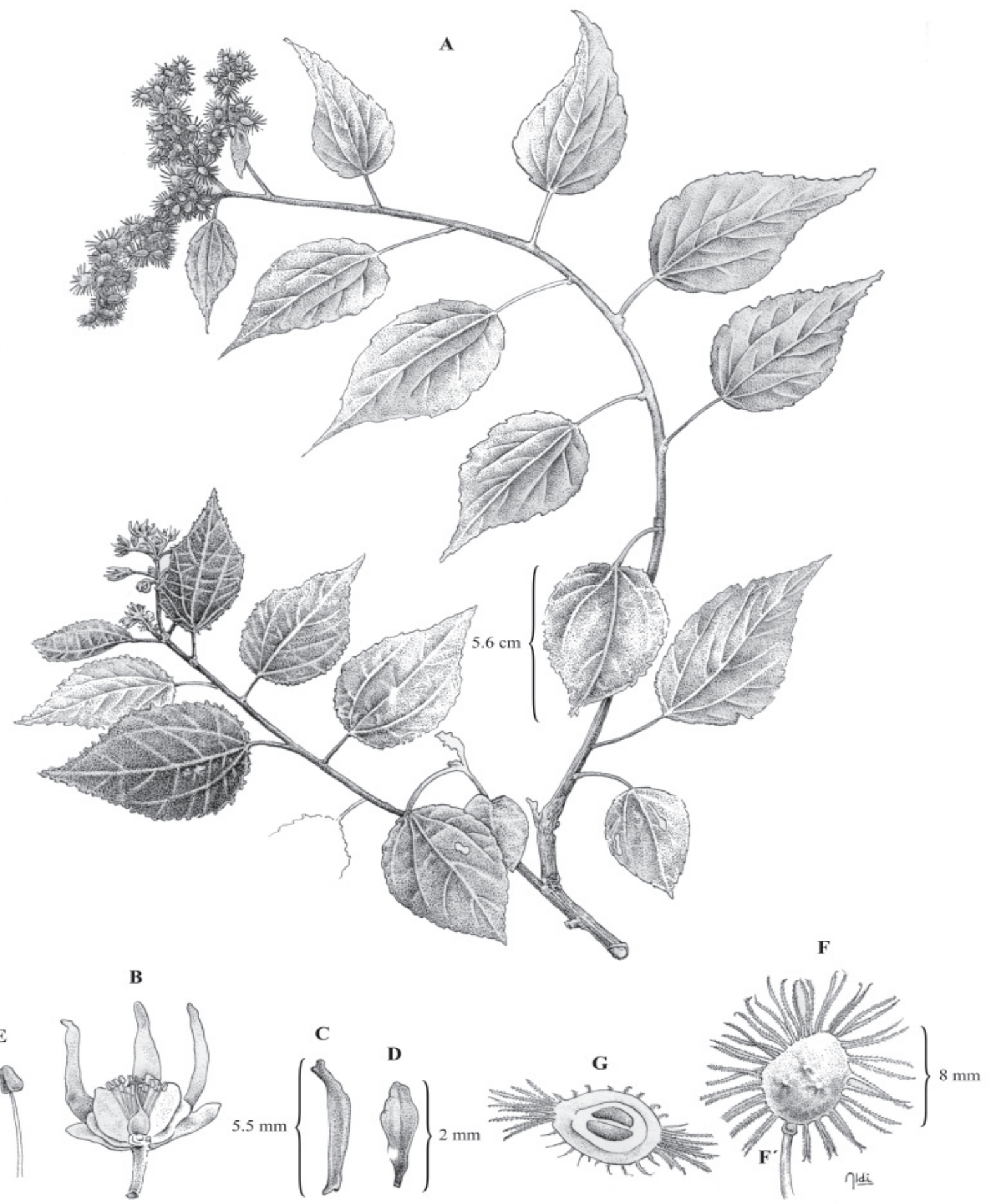

Figura 1. Heliocarpus parvimontis sp. nov. A. Rama con hojas, flores y frutos. B. Flor vista lateralmente. C. Sépalo. D. Pétalo. E. Estambre. F. Vista lateral del fruto. F'. Androginóforo. G. Corte transversal del fruto mostrando las semillas (basado en E. Moreno et al. 581 y 1062$)$. 
Clave sinóptica para identificación de las especies de Heliocarpus con ovario y fruto sésiles sobre un androginóforo.

1. Lámina de las hojas siempre 3-lobada, 3-nervada.

2. Lámina de las hojas de color blanquecino, con el envés tomentoso y densamente estrelladopubescente; cáliz con 5 sépalos.

2. Lámina de las hojas de color verde, con el envés no tomentoso, escasamente estrelladopubescente; cáliz con 4 sépalos.

1. Lámina de las hojas no lobada, rara vez 3-lobada, 5(-7)-nervada.

3. Base de las hojas cordada o subcordada, nunca redondeada o cuneada.

4. Lámina de las hojas glabra en ambas superficies; estambres ca. 40

H. palmeri

4. Lámina de las hojas glabrescente en el haz, tomentosa en el envés; estambres ca. 20..........

H. attenuatus

3. Base de las hojas redondeada o cuneada, raramente cordada o subcordada.

5. Lámina de las hojas escasamente estrellado-pubescente en ambas superficies,

de color verde oscuro y de consistencia papirácea; margen dentado-mucronado, con 3 pares de dientes basales glandulares; estambres (30-)40; polen tricolpado.......

H. occidentalis

5. Lámina de las hojas densamente estrellado-pubescente en ambas superficies,

de color verde claro y de consistencia aterciopelada; margen eroso, con la mayoría de los lóbulos glandulares; estambres ca. 50; polen tricolporado

H. parvimontis

Cuadro 1. Comparación de caracteres distintivos entre $H$. occidentalis y H. parvimontis

\begin{tabular}{lll}
\hline Carácter & H. occidentalis & H.parvimontis \\
\hline $\begin{array}{l}\text { Corteza } \\
\text { externa }\end{array}$ & Exfoliante & No exfoliante \\
Flor & $\begin{array}{l}\text { Sépalos linear- } \\
\text { lanceolados. } \\
\text { Apéndices de los } \\
\text { sépalos de ca. 1 }\end{array}$ & Sépalos lanceolados. \\
mm de largo. \\
$\begin{array}{l}\text { Pétalos linear- } \\
\text { espatulados. }\end{array}$ & Pétalos obovados. \\
& $\begin{array}{l}\text { Núm. estambres: } \\
(30-) 40 .\end{array}$ & Núm. estambres: ca. 50. \\
\hline
\end{tabular}

de bosque tropical caducifolio y en ecotonías de bosque tropical caducifolio-bosque de Quercus en el estado de Guerrero, en altitudes de 1480 a 1590 m, en laderas de pendiente moderadas, con orientación NNE, con una distribución hasta el momento exclusiva a la región de la depresión del río Balsas. Por otra parte, $H$. occidentalis se conoce de bosques de galería, vegetación secundaria y de los bosques tropicales caducifolio y subcaducifolio en los estados de Nayarit, Jalisco, Colima, Michoacán Guerrero, México, Oaxaca y Chiapas, en elevaciones desde el nivel del mar hasta los $1250 \mathrm{~m}$, con distribución restringida a la vertiente del Pacífico en los estados antes mencionados.

\section{Agradecimientos}

A los siguientes investigadores por sus sugerencias para mejorar el manuscrito: Dra. Nelly Diego Pérez, Biól. Óscar Polaco Ramos, M. en C. Rafael Torres Colín y Dr. Sergio Zamudio Ruiz; al Dr. José Luis Villaseñor Ríos por la elaboración de la diagnosis en latín y por sus valiosos comentarios, así como a los de un revisor anónimo, y al M. en A. Aldi de Oyarzábal, por la elaboración de la excelente ilustración de la especie.

\section{Literatura citada}

Gual, D. M. 1998. La familia Tiliaceae Juss., en el estado de Guerrero, México. Tesis, Maestría (biología vegetal) Facultad de Ciencias, UNAM, México, D. F. 170 p.

Lay, K. K. 1949. A revision of the genus Heliocarpus L. Annals of the Missouri Botanical Garden 36:507-541.

Mabberley, D. L. 2002. The plant-book. A portable dictionary of the higher plants. Cambridge University Press, Cambrige $707 \mathrm{p}$.

McVaugh, R. 2001. Ochnaceae to Loasaceae. In Flora NovoGaliciana, vol. 3, W. R. Anderson (ed.). The University of Michigan Press, Ann Arbor. 751 pp.

Robyns, A. 1964. Flora of Panama. Tiliaceae. Annals of the Missouri Botanical Garden 51:1-35. 